\title{
Combined overexpression of cadherin 6, cadherin 11 and cluster of differentiation 44 is associated with lymph node metastasis and poor prognosis in oral squamous cell carcinoma
}

\author{
CHAO MA, JI-ZHI ZHAO, RUN-TAI LIN, LIAN ZHOU, YONG-NING CHEN, LI-JIANG YU, \\ TIAN-YIN SHI, MU WANG, MAN-MAN LIU, YAO-RAN LIU and TAO ZHANG \\ Department of Stomatology, Peking Union Medical College Hospital, Beijing 100730, P.R. China
}

Received October 21, 2016; Accepted February 28, 2018

DOI: $10.3892 / \mathrm{ol} .2018 .8509$

\begin{abstract}
Oral squamous cell carcinoma (OSCC) is a highly invasive lesion that frequently metastasizes to the cervical lymph nodes and is associated with a poor prognosis. Several adhesion factors, including cadherin 6 (CDH6), cadherin 11 (CDH11) and cluster of differentiation 44 (CD44), have been reported to be involved in the invasion and metastasis of multiple types of cancer. Therefore, the aim of the present study was to determine the expression of CDH6, CDH11 and CD44 in tumor tissues from patients with OSCC, and whether this was associated with the metastasis and survival of OSCC. The mRNA expression of the human tumor metastasis-related cytokines was examined by reverse transcription-quantitative polymerase chain reaction (RT-qPCR) in OSCC tumors with or without lymph node metastasis ( $\mathrm{n}=10 /$ group). The expression of CDH6, CDH11 and CD44 in 101 OSCC and 10 normal oral mucosa samples was examined by immunohistochemical staining. The association between overall and disease-specific survival times of patients with OSCC and the expression of these three proteins was evaluated using Kaplan-Meier curves and the log-rank test. RT-qPCR results indicated that the mRNA expression of CDH6, CDH11 and CD44 was increased in OSCC patients with lymph node metastasis (2.93-, 2.01- and
\end{abstract}

Correspondence to: Dr Tao Zhang, Department of Stomatology, Peking Union Medical College Hospital, 1 Shuai Fu Yuan, Dongcheng, Beijing 100730, P.R. China

E-mail: drtzhang@126.com

Abbreviations: OSCC, oral squamous cell carcinoma; LNM, lymph node metastasis; CDH6, cadherin 6; $\mathrm{CDH} 11$, cadherin 11; $\mathrm{PCa}$, prostate cancer; IHC, immunohistochemical; SABC, streptavidin-biotin complex; RT-qPCR, reverse transcription-quantitative polymerase chain reaction; MMPs, matrix metalloproteinases; EMT, epithelial-mesenchymal transition; Akt, protein kinase B; PI3K, phosphatidylinositol 3-kinase; MAPK, mitogen-activated protein kinase; STAT, signal transducer and activator of transcription

Key words: cadherin 6, cadherin 11, cluster of differentiation 44, oral squamous cell carcinoma, metastasis, prognosis 1.92-fold; $\mathrm{P}<0.05)$. Overexpression of CDH6, CDH11 and CD44 was observed in 31/35 (89\%), 25/35 (71\%) and 31/35 (89\%) patients, respectively. The number of OSCC patients with lymph node metastasis exhibiting CDH6, CDH11 and CD44 overexpression was significantly higher than the number of patients without lymph node metastasis exhibiting overexpression of these proteins $(\mathrm{P}=0.017, \mathrm{P}=0.038$ and $\mathrm{P}=0.007$, respectively). OSCC patients with high co-expression of CDH6, CDH11 and CD44 exhibited lower disease-specific survival times $\left(\mathrm{P}=0.047 ; \chi^{2}=3.933\right)$ when compared with OSCC patients with low co-expression of these adhesion factors. CDH6, CDH11 and CD44 serve important roles in OSCC metastasis and the combined use of these factors as biomarkers may improve the accuracy of the prediction of cancer metastases and prognosis.

\section{Introduction}

Oral squamous cell carcinoma (OSCC) is one of the most common subtypes of all malignant head and neck tumors worldwide (1). OSCC is a highly invasive lesion that frequently metastasizes to cervical lymph nodes (2). Metastasis to regional lymph nodes and distant sites occurs in $\sim 40 \%$ of patients with oral cancer and is associated with a poor prognosis $(3,4)$. At present, only $25-40 \%$ of patients with lymph node metastasis (LNM) achieve 5-year survival, compared with $\sim 90 \%$ of patients without metastasis (5).

Metastasis is the result of complicated events, in which the dysfunction of epithelial cell-cell adhesion is known to be critical for tumor invasion and metastasis (6). Cadherins, as a major class of cell-cell adhesion molecules, regulate the adhesion and migration of cells in a calcium-dependent manner (7). Reduction of E-cadherin expression predicts the loss of epithelial cell adhesion (8), which is a prognostic factor for head and neck squamous cell carcinoma, according to a systematic review with meta-analysis (9). Cadherin 6 (CDH6) is a class II cadherin and its upregulation reportedly promotes the motility and invasion of several cancer cells (10-12). Cadherin 11 (CDH11), a mesenchymal cadherin, is upregulated during prostate cancer (PCa) progression and bone metastasis (13). CDH11 expression increased the migration and invasion of PCa cells and enabled PCa cells to intercalate into an osteoblast 
monolayer (14). However, the roles of these two proteins in mediating cell migration in OSCC remain unclear. CD44 is a transmembrane glycoprotein and a cell adhesion molecule that serves a crucial role in the differentiation, invasion and metastasis of various types of tumor cell $(15,16)$. CD44 is also involved in the epithelial-mesenchymal transition (EMT), which is associated with metastasis.

Recent studies have suggested that the increase in CD44 expression in OSCC is associated with increased metastasis and decreased survival $(17,18)$. However, the association between CDH6, CDH11 and CD44 expression in OSCC has not previously been investigated. Therefore, the aim of the present study was to determine whether these adhesion factors may serve as potential prediction factors for OSCC metastasis and prognosis, in order to better understand the underlying pathogenesis of this malignancy and potentially to improve the prognosis and treatment outcome of patients with OSCC.

\section{Materials and methods}

Patients and tumor procurement. A total of 101 patients with OSCC who were treated at the Department of Oral and Maxillofacial Surgery, Peking Union Medical College Hospital (Beijing, China) between March 2006 and December 2010 were retrospectively enrolled in the present study. Tumors were pathologically staged according to the American Joint Cancer Committee staging system (19) Within 30 min after surgical extirpation, tissues were frozen in liquid nitrogen, and the study was approved by the Ethics Committee of Peking Union Medical College. The clinicopathological information of the patients from whom the tissues were obtained is presented in Table I.

Reverse transcription-quantitative polymerase chain reaction $(R T-q P C R)$. Tumor tissue samples with or without LNM (n=10/group) were homogenized, and total RNA was extracted using TRIzol reagent (Invitrogen; Thermo Fisher Scientific, Inc., Waltham, MA, USA) and was further purified using the RNeasy RNA Extraction Mini kit (Qiagen GmbH, Hilden, Germany). RNA samples were converted into first strand cDNA using an $\mathrm{RT}^{2}$ First Strand kit, according to the manufacturer's protocols (SABiosciences; Qiagen $\mathrm{GmbH}$ ). Quantitative gene expression was analyzed by qPCR, performed on an ABI Prism 7900 HT (Applied Biosystems; Thermo Fisher Scientific, Inc.). The optimized parameters for PCR were: $95^{\circ} \mathrm{C}$ for $2 \mathrm{~min}, 94^{\circ} \mathrm{C}$ for $10 \mathrm{sec}, 61.5^{\circ} \mathrm{C}$ for $30 \mathrm{sec}$ and $72^{\circ} \mathrm{C}$ for $40 \mathrm{sec}$ for 40 cycles). The assay used an $\mathrm{RT}^{2}$ Profiler PCR array system ( $\mathrm{RT}^{2}$ Profiler $^{\mathrm{TM}}$ PCR Array Human Tumor Metastasis (PAHS-028Z); SABiosciences; Qiagen $\mathrm{GmbH}$ ) that contained a panel of 84 genes and SYBRGreen qPCR detection method and was performed according to the manufacturer's protocols. Quality controls were all within the recommended range. Data were analyzed by the $2^{-\Delta \Delta \mathrm{Cq}}$ method (20).

Immunohistochemical (IHC) staining. IHC staining was performed by the streptavidin-biotin complex (SABC) method using $4 \%$ formalin-fixed (fixed for $48 \mathrm{~h}$ at $25^{\circ} \mathrm{C}$ ), paraffin-embedded $4-\mu \mathrm{m}$ tissue sections. Tissue sections were heat-immobilized at $60^{\circ} \mathrm{C}$ for $30 \mathrm{~min}$ and deparaffinized in
Table I. Clinicopathological characteristics in patients with oral squamous cell carcinoma $(n=101)$.

\begin{tabular}{lc}
\hline Variables & No. patients $(\%)$ \\
\hline Age, years & \\
$>60$ & $53(52.5)$ \\
$<60$ & $48(47.5)$ \\
Sex & \\
Male & $65(85.1)$ \\
Female & $36(14.9)$ \\
Location & \\
Tongue & $45(44.6)$ \\
Gingiva & $23(22.8)$ \\
Floor of mouth & $17(16.8)$ \\
Buccae & $14(13.9)$ \\
Hard palate & $2(1.9)$ \\
Lymph node metastasis & \\
Yes & $35(34.7)$ \\
No & $66(65.3)$ \\
Tumor stage & \\
I & $25(24.8)$ \\
II & $34(33.6)$ \\
III & $19(18.8)$ \\
IV & $23(22.8)$ \\
Differentiation & \\
Well & $38(37.6)$ \\
Moderate & $50(49.5)$ \\
Poor & $13(12.9)$ \\
Smoking & \\
Yes & \\
No & \\
Alcohol & \\
Yes & \\
No & \\
\hline
\end{tabular}

xylene and rehydrated through a descending ethanol series $(100,95,90,80$ and $70 \%)$ at room temperature for $5 \mathrm{~min}$ at each concentration. Following the blocking of endogenous peroxidase activity with $0.3 \%$ hydrogen peroxide for $10 \mathrm{~min}$, the sections were blocked for $1 \mathrm{~h}$ at room temperature with $5 \%$ bovine serum albumin, prior to being incubated with primary rabbit anti-CDH6 antibody (dilution, 1:100; cat. no. ab64917; Abcam, Cambridge, MA, USA), mouse anti-CDH11 antibody (dilution, 1:50; cat. no. ab151446; Abcam) or rabbit anti-CD44 antibody (dilution, 1:100; cat. no. ab51037; Abcam) for $24 \mathrm{~h}$ at $4^{\circ} \mathrm{C}$. The slides were rinsed with phosphate-buffered saline (PBS) three times and were incubated with a goat anti-rabbit horseradish peroxidase-conjugated secondary antibody (dilution, 1:500; cat. no. ZB-2010; OriGene Technologies, Inc., Beijing, China) or a goat anti-mouse secondary antibody (cat. no. ZB-2305; OriGene Technologies, Inc.) for $30 \mathrm{~min}$ at room temperature. Following incubation with SABC for $20 \mathrm{~min}$ at room temperature, the sections were exposed to 
Table II. Expression profiling of human tumor metastasis-related gene in oral squamous cell carcinoma tissues with or without metastasis, as determined by reverse transcription-quantitative polymerase chain reaction. Fold-change was calculated using the $2^{-\Delta \Lambda \mathrm{Cq}}$ method. $n=10 /$ group.

\begin{tabular}{|c|c|c|c|}
\hline Gene abbreviations & Full gene name & Fold-change & P-value \\
\hline \multicolumn{4}{|l|}{ Upregulated } \\
\hline APC & Adenomatous polyposis coli & 1.25 & $0.035^{\mathrm{a}}$ \\
\hline CD44 & CD44 molecule & 1.92 & $0.011^{\mathrm{a}}$ \\
\hline CDH6 & Cadherin 6 & 2.93 & $0.007^{\mathrm{b}}$ \\
\hline CDH11 & Cadherin 11 & 2.01 & $0.009^{\mathrm{b}}$ \\
\hline CTNNA1 & Catenin $\alpha 1$ & 1.49 & $0.034^{\mathrm{a}}$ \\
\hline FAT1 & FAT tumor suppressor homolog 1 & 1.76 & $0.032^{\mathrm{a}}$ \\
\hline ITGA7 & Integrin, $\alpha 7$ & 2.14 & $0.022^{\mathrm{a}}$ \\
\hline FGFR4 & Fibroblast growth factor receptor 4 & 1.34 & $0.040^{\mathrm{a}}$ \\
\hline MDM2 & Mdm2 p53 binding protein homolog & 1.92 & $0.009^{\mathrm{b}}$ \\
\hline MMP7 & Matrix metallopeptidase 7 (matrilysin) & 2.36 & $0.029^{\mathrm{a}}$ \\
\hline MMP9 & Matrix metallopeptidase 9 & 5.11 & $0.001^{\mathrm{b}}$ \\
\hline MMP13 & Matrix metallopeptidase 13 & 2.51 & $0.008^{\mathrm{b}}$ \\
\hline CCL2 & Chemokine (C-C motif) 2(MCP-1) & 1.98 & $0.013^{\mathrm{a}}$ \\
\hline CCL3 & Chemokine (C-C motif) 3(MIP-1A) & 2.16 & $0.021^{\mathrm{a}}$ \\
\hline CCL5 & Chemokine (C-C motif) 5(RANTES) & 2.71 & $0.004^{\mathrm{a}}$ \\
\hline CCL7 & Chemokine (C-C motif) 7(MCP-3) & 1.74 & $0.023^{\mathrm{a}}$ \\
\hline CXCR4 & Chemokine (C-X-C motif) receptor 4 & 1.72 & $0.019^{\mathrm{a}}$ \\
\hline MTA1 & Metastasis-associated 1 & 1.32 & 0.061 \\
\hline TNFSF10 & Tumor necrosis factor superfamily, member 10 & 1.13 & 0.081 \\
\hline TP53 & Tumor protein $\mathrm{p} 53$ & 1.43 & $0.021^{\mathrm{a}}$ \\
\hline TSHR & Thyroid stimulating hormone receptor & 1.65 & $0.018^{\mathrm{a}}$ \\
\hline \multicolumn{4}{|l|}{ Downregulated } \\
\hline CDH1 & E-cadherin (epithelial) & -1.13 & $0.083^{\mathrm{a}}$ \\
\hline BRMS1 & Breast cancer metastasis suppressor 1 & -1.42 & $0.021^{\mathrm{a}}$ \\
\hline TIMP3 & TIMP metallopeptidase inhibitor 3 & -0.92 & 0.102 \\
\hline GNRH1 & Gonadotropin-releasing hormone 1 & -0.61 & $0.050^{\mathrm{a}}$ \\
\hline HPSE & Heparanase & -0.66 & $0.034^{\mathrm{a}}$ \\
\hline
\end{tabular}

${ }^{\mathrm{a}} \mathrm{P}<0.05,{ }^{\mathrm{b}} \mathrm{P}<0.01$, Student's t-test.

3,3'-diaminobenzidine for $1 \mathrm{~min}$, counterstained with hematoxylin at room temperature for $15 \mathrm{sec}$, mounted in neutral gum and images were captured using a Nikon Eclipse E600 microscope (Nikon Corporation, Tokyo, Japan). PBS was used instead of the primary antibody as a negative control.

Evaluation of immunohistochemistry was quantified by two pathologists, who were blinded to all patient diagnoses. The staining intensity was estimated in a 4-step scale as previously reported $(0$, no staining; 1 , weak intensity; 2 , moderate intensity; and 3, strong intensity) (21). The fraction of stained cells was scored according to the following criteria: Score 0, $<10 \%$ positive cancer cells; score $1,11-50 \%$ positive cancer cells; score $2,51-80 \%$ positive cancer cells; and score $3,>80 \%$ positive cancer cells. The final staining score was assigned based on the multiplication of the staining intensity and the percentage of positive cells, and was graded as follows: 0, 0; $1,1-3 ; 2,5-6$; and $3,7-9$. Scores of 0 or 1 were classed as low expression, and scores 2 or 3 were classed as high expression for further analysis.
Statistical analysis. All experiments were repeated at least three times. Data were analyzed using SPSS software (version 20.0; SPSS, Inc., Chicago, IL, USA) and GraphPad prism software (GraphPad Software, Inc., La Jolla, CA, USA). Significance values were assigned using Student's t-tests and the $\mathrm{c}^{2}$ test was used to compare the results between the two groups and the associations with clinicopathological features, including age, sex, histopathological grade, LNM and tumor stage. $\mathrm{P}<0.05$ was considered to indicate a statistically significant difference.

\section{Results}

Patient characteristics. The patient cohort included 65 males and 36 females, with a median age of 62 years (range, 34-85 years). Primary OSCC tumors were most frequently identified on the tongue $(45 / 101 ; 44.6 \%)$, followed by the gingiva $(23 / 101 ; 22.8 \%)$, the floor of the mouth $(17 / 101 ; 16.8 \%)$, the buccal $(14 / 101 ; 13.9 \%)$ and the hard palate $(2 / 101 ; 1.9 \%)$. 


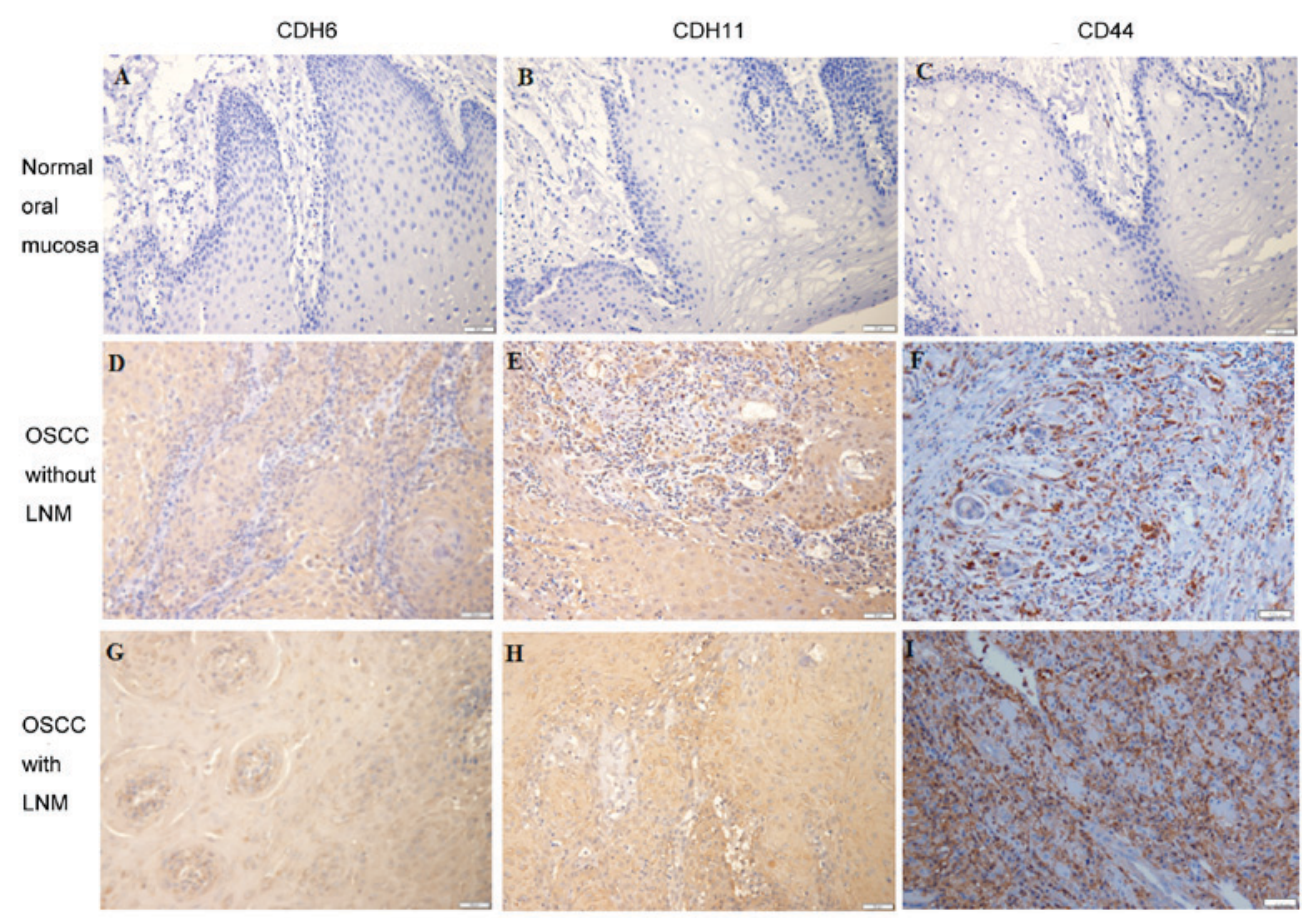

Figure 1. Expression of CDH6, CDH11 and CD44 in normal tissue and in OSCC with and without LNM. Photomicrographs demonstrate representative examples of (A) CDH6, (B) CDH11 and (C) CD44 expression in normal oral mucosa. Representative examples of (D) CDH6, (E) CDH11 and (F) CD44 expression in OSCC without LNM. Representative examples of (G) CDH6, (H) CDH11 and (I) CD44 expression in OSCC with LNM. Magnification, x200; scale bar, $50 \mu \mathrm{m}$. CDH, cadherin; CD44, cluster of differentiation 44; OSCC, oral squamous cell carcinoma; LNM, lymph node metastasis.

LNM occurred in 35/101 patients (34.7\%). Further patient characteristics are presented in Table I.

Expression of tumor metastasis cytokines involved in cell adhesion and inflammation is increased in OSCC tumors with $L N M$. The expression of 84 tumor metastasis cytokines was analyzed using RT-qPCR analysis. CDH6, CDH11 and CD44 mRNA expression was significantly increased in the OSCC patients with LNM compared with the OSCC patients without LNM (2.93-, 2.01- and 1.92-fold; $\mathrm{P}<0.05)$, which was assessed by Student's t-test. Including CDH6, CDH11 and CD44, 21 genes were upregulated and 5 others were downregulated in OSCC tumors with LNM compared with OSCC tumors without LNM (Table II). Of the genes that were upregulated, 7 were associated with cell-cell adhesion (adenomatous polyposis coli, CD44, CDH6, CDH11, catenin $\alpha 1$, FAT tumor suppressor homolog 1 and integrin subunit $\alpha 7$ ). The expression of 3 matrix metallopeptidases (MMPs) was increased (MMP7, MMP9 and MMP13), which was reported to be associated with tumor LNM (22-24). The majority of the upregulated chemokines belong to the chemokine ligand subfamily and are involved in macrophage recruitment [monocyte chemoattractant protein (MCP)-1, macrophage inflammatory protein- $1 \alpha$, regulated on activation, normal $\mathrm{T}$ cell expressed and secreted and MCP-3] (25), while the other three are chemokine receptors (C-X-C chemokine receptor type 4, fibroblast growth factor receptor 4 and thyroid-stimulating hormone receptor). Three genes involved in apoptosis (metastasis-associated 1, tumor necrosis factor superfamily member 10 and tumor protein $\mathrm{p} 53$ ) were also upregulated. In contrast to the increased expression of MMPs, two extracellular matrix proteins (heparanase precursor and tissue inhibitor of metalloproteinase-3), which are MMP inhibitors, were downregulated. The expression of gonadotrophin-releasing hormone 1 , a growth factor included in the array, was decreased (Table II).

CDH6, CDH11 and CD44 expression, detected by IHC staining, exhibited a significant positive association with cervical LNM in tumor tissues. The expression of CDH6, CDH11 and CD44 in specimens from patients with OSCC was determined using IHC staining. As demonstrated by Fig. 1, there was almost no staining in normal mucosa for CDH6 (Fig. 1A), CDH11 (Fig. 1B) or CD44 (Fig. 1C). However, these adhesion factors were localized to the nucleus and the cytoplasm of tumor cells, and high expression of CDH6 (44/66, 66\%; Fig. 1D), CDH11 (33/66, 50\%; Fig. 1E) and CD44 (37/66, $56 \%$; Fig. $1 \mathrm{~F}$ ) was observed in 66 OSCC cases without LNM (Table III). Additionally, the expression of CDH6 (31/35, 89\%; Fig. 1G), CDH11 (25/35, 71\%; Fig. 1H) and CD44 (31/35, 89\%; Fig. 1I) was significantly increased in tumor cells with LNM, compared with those without LNM ( $\mathrm{n}=35 ; \mathrm{P}<0.001$; Table III). These results indicated that high expression of CDH6, CDH11 and CD44 was significantly associated with LNM in OSCC (Table III).

Associations between CDH6, CDH11 and CD44 expression and clinicopathological factors. The associations between CDH6, CDH11 and CD44 protein expression and clinicopathological data were assessed using the $\mathrm{c}^{2}$ test and are summarized in Table IV. CDH6, CDH11 and CD44 protein expression was significantly associated with $\mathrm{LNM}(\mathrm{P}=0.017$, $\mathrm{P}=0.038$ and $\mathrm{P}=0.001$, respectively). OSCC cases with LNM 
Table III. Immunohistochemical analysis of CDH6, CDH11 and CD44 expression in OSCC. Association between expression of CDH6, CDH11 or CD44 and tumor metastasis was analyzed using SPSS software.

\begin{tabular}{llrl}
\hline & \multicolumn{2}{c}{$\begin{array}{c}\text { No. of } \\
\text { patients }(\%)\end{array}$} & \\
\cline { 2 - 3 } Variables & High & Low & P-value \\
\hline CDH6 & & & \\
OSCC without LNM & $44(66)$ & $22(34)$ & $0.017^{\text {a }}$ \\
OSCC with LNM & $31(89)$ & $4(11)$ & \\
CDH11 & & & \\
OSCC without LNM & $33(50)$ & $33(50)$ & $0.038^{\text {a }}$ \\
OSCC with LNM & $25(71)$ & $10(29)$ & \\
CD44 & & & \\
OSCC without LNM & $37(56)$ & $29(44)$ & $0.001^{\text {b }}$ \\
OSCC with LNM & $31(89)$ & $4(11)$ & \\
\hline
\end{tabular}

${ }^{\mathrm{a}} \mathrm{P}<0.05,{ }^{\mathrm{b}} \mathrm{P}<0.01$, as determined by the $\chi^{2}$ test. OSCC, oral squamous cell carcinoma; $\mathrm{CDH}$, cadherin; CD44, cluster of differentiation 44; LNM, lymph node metastasis.

exhibited higher rates of elevated CDH6, CDH11 and CD44 protein expression. In addition, tumor stage was significantly associated with these adhesion factors $(\mathrm{P}=0.002, \mathrm{P}=0.016$ and $\mathrm{P}=0.018$, respectively). However, no significant differences were identified between the expression of these proteins and the degree of tumor differentiation, age or sex $(\mathrm{P}>0.05)$.

Associations among $\mathrm{CDH6}, \mathrm{CDH} 11$ and $\mathrm{CD} 44$ protein expression in OSCC. In the present study, the associations among the protein expression of CDH6, CDH11 and CD44 were assessed using the $\chi^{2}$ test. As demonstrated by Table V, 56/101 patients with OSCC exhibited high expression and 14 exhibited low expression of CD44 and CDH6. The association between CD44 and CDH6 expression was statistically significant $(r=0.266 ; P=0.008)$. Similarly, there was a statistically significant association between the expression of CD44 and CDH11 ( $\mathrm{r}=0.254 ; \mathrm{P}=0.011$ ), with $45 / 101$ patients with OSCC exhibiting a high expression. These results indicated the co-association between CDH6, CDH11 and CD44.

Association between CDH6, CDH11 and CD44 expression and survival in patients with OSCC. No significant associations between the 5-year overall survival rate of patients with OSCC, and CDH6, CDH11 or CD44 expression were identified (Fig. 2A-C). However, the 5-year disease-specific survival rate of OSCC patients with high CDH6 and CD44 expression was significantly decreased when compared with those exhibiting low expression [CDH6 $\left(\mathrm{P}=0.018 ; \chi^{2}=5.534\right)$ and CD44 ( $\left.\mathrm{P}=0.031 ; \chi^{2}=4.622\right)$; Fig. 2D and F]. As CDH6, CDH11 and CD44 were revealed to be associated with LNM in the present study, the association between patient survival and the co-expression of these factors was also investigated. The results revealed that the co-expression of CDH6, CDH11 and CD44 was not significantly associated with overall survival
(Fig. 3A). However, the 5-year disease-specific survival rate of patients with high co-expression of these proteins was decreased when compared with that of patients exhibiting low co-expression ( $\mathrm{P}=0.047 ; \chi^{2}=3.933$; Fig. 3B).

\section{Discussion}

The primary cause of mortality in OSCC is metastasis, occurring primarily via the lymphatic system. The impact of this depends on the size and site of the primary tumor, the Tumor-Node-Metastasis (TNM) stage (19), the depth of invasion, perineural invasion, patient compliance, biological tumor markers and tumor grade (26). Intercellular adhesion is mediated by a family of glycoproteins known as cadherins, which serve an important role in the migration and dissemination of cells during tumor progression and metastasis (27). It is well-known that loss of E-cadherin and increased expression of $\mathrm{N}$-cadherin is associated with tumor cell invasion in oral and ovarian cancer $(28,29)$. By contrast, other mesenchymal-associated cadherins and adhesion factors, including CDH6, CDH11 and CD44, which have been proven to be able to interfere with epithelial cell-cell adhesion and to promote cancer cell invasion and metastasis, are often overexpressed in ovarian cancer (30-32). Until now, however, the precise role of the three factors in OSCC has not received a great deal of attention. The present study investigated the role of three factors in the metastasis of OSCC using IHC staining and RT-qPCR. It was revealed that $\mathrm{CDH}$, $\mathrm{CDH} 11$ and $\mathrm{CD} 44$ expression in tumor cells was associated with LNM in patients with OSCC.

In the present study, the mRNA expression of 84 potential human tumor metastatic factors, including CDH6, CDH11 and CD44, was observed in OSCC tissues with or without LNM. CDH6, CDH11 and CD44 mRNA expression was significantly increased in the OSCC patients with LNM, and 18 other upregulated and 5 downregulated cytokines were observed. CDH6, CDH11 and CD44 protein expression was subsequently examined in 10 normal oral mucosae and 101 OSCC tissues, including 35 cases with LNM, using IHC staining. These results demonstrated that no cases of normal oral mucosa exhibited high protein expression of these factors. However, high protein expression of CDH6, CDH11 and CD44 was observed in 89, 71 and $89 \%$ of 35 cases, respectively, of OSCC with LNM compared with 66,50 and $56 \%$ of 66 OSCC cases, respectively, without LNM. The association between CDH6, CDH11 or CD44 protein expression and several clinicopathological indicators was assessed. The overexpression of these factors was associated with aggressive histopathological features, including LNM and advanced TNM stages, whereby OSCC patients with an advanced TNM stage (III-IV) and LNM exhibited higher expression of these proteins. However, there was no association between protein expression and age, sex or tumor differentiation. Furthermore, the present study observed that the prognostic value may be largely enhanced by co-evaluating the expression of these three proteins in patients with OSCC. These results were in line with those of previous studies in other types of cancer (29-31), indicating that CDH6, CDH11 and CD44 may be either directly or indirectly involved in the metastasis of OSCC. Therefore, it is reasonable to combine the expression of these three proteins as predictive parameters for improved evaluation of the progression of OSCC. 
Table IV. Association between expression of CDH6, CDH11 or CD44 and clinicopathological characteristics in patients with oral squamous cell carcinoma $(\mathrm{n}=101)$.

\begin{tabular}{|c|c|c|c|c|c|c|c|c|c|}
\hline \multirow[b]{2}{*}{ Variable } & \multicolumn{3}{|c|}{ CDH6 } & \multicolumn{3}{|c|}{ CDH11 } & \multicolumn{3}{|c|}{ CD44 } \\
\hline & High & Low & P-value & High & Low & P-value & High & Low & P-value \\
\hline Patient number & 75 & 26 & & 58 & 43 & & 68 & 33 & \\
\hline \multicolumn{10}{|l|}{ Age, years } \\
\hline$>60$ & 40 & 13 & \multirow[t]{2}{*}{0.769} & 32 & 21 & \multirow[t]{2}{*}{0.528} & 37 & 16 & \multirow[t]{2}{*}{0.576} \\
\hline$<60$ & 35 & 13 & & 26 & 22 & & 31 & 17 & \\
\hline \multicolumn{10}{|l|}{ Sex } \\
\hline Male & 47 & 18 & \multirow[t]{2}{*}{0.547} & 40 & 25 & \multirow[t]{2}{*}{0.261} & 40 & 25 & \multirow[t]{2}{*}{0.096} \\
\hline Female & 28 & 8 & & 18 & 18 & & 28 & 8 & \\
\hline \multicolumn{10}{|c|}{ Lymph node metastasis } \\
\hline Yes & 31 & 4 & \multirow[t]{2}{*}{$0.017^{\mathrm{a}}$} & 25 & 10 & \multirow[t]{2}{*}{$0.038^{\mathrm{a}}$} & 31 & 4 & \multirow[t]{2}{*}{$0.001^{\mathrm{b}}$} \\
\hline No & 44 & 22 & & 33 & 33 & & 37 & 29 & \\
\hline \multicolumn{10}{|c|}{ Tumor (AJCC) stage } \\
\hline$>$ II & 38 & 4 & \multirow[t]{2}{*}{$0.002^{\mathrm{b}}$} & 30 & 12 & \multirow[t]{2}{*}{$0.016^{\mathrm{a}}$} & 33 & 9 & \multirow[t]{2}{*}{$0.018^{\mathrm{a}}$} \\
\hline$<$ II & 37 & 22 & & 28 & 31 & & 33 & 26 & \\
\hline \multicolumn{10}{|l|}{ Differentiation } \\
\hline Well & 26 & 12 & \multirow[t]{3}{*}{0.067} & 23 & 15 & \multirow[t]{3}{*}{0.859} & 29 & 9 & \multirow[t]{3}{*}{0.853} \\
\hline Moderately & 35 & 15 & & 26 & 24 & & 30 & 20 & \\
\hline Poorly & 10 & 3 & & 9 & 4 & & 9 & 4 & \\
\hline \multicolumn{10}{|l|}{ Smoking } \\
\hline Yes & 52 & 18 & \multirow[t]{2}{*}{0.992} & 42 & 28 & \multirow[t]{2}{*}{0.278} & 47 & 23 & \multirow[t]{2}{*}{0.953} \\
\hline No & 23 & 8 & & 15 & 16 & & 21 & 10 & \\
\hline \multicolumn{10}{|l|}{ Alcohol } \\
\hline No & 45 & 15 & \multirow[t]{2}{*}{0.836} & 33 & 27 & \multirow[t]{2}{*}{0.551} & 38 & 22 & \multirow[t]{2}{*}{0.301} \\
\hline Yes & 30 & 11 & & 25 & 16 & & 30 & 11 & \\
\hline
\end{tabular}

${ }^{\mathrm{a}} \mathrm{P}<0.05,{ }^{\mathrm{b}} \mathrm{P}<0.01$, as determined by the $\chi^{2}$ test using SPSS software. CDH, cadherin; CD44, cluster of differentiation 44; AJCC, American Joint Committee on Cancer.

Table V. Associations between CD44 protein expression and the expression of CDH6 and CDH11 in patients with oral squamous cell carcinoma $(n=101)$.

\begin{tabular}{lcccc}
\hline $\begin{array}{l}\text { Protein } \\
\text { expression } \\
\text { (no.) }\end{array}$ & High (n=68) & Low (n=33) & rФ & P-value \\
\cline { 2 - 5 } & & & 0.266 & $0.007^{\mathrm{a}}$ \\
\hline CDH6 & 56 & 19 & & \\
High (75) & 12 & 14 & & \\
Low (26) & & & 0.254 & $0.01^{\mathrm{a}}$ \\
CDH11 & 45 & 13 & & \\
High (58) & 23 & 20 & & \\
Low (43) & & & & \\
\hline
\end{tabular}

a $\mathrm{P}<0.01$, as determined by the $\chi^{2}$ test using SPSS software. CD44, cluster of differentiation 44; $\mathrm{CDH}$, cadherin.

CDH6 and CDH11 expression have been revealed to be associated with aggressive tumor cell migration and a poorer patient outcome (30-32). However, the underlying mechanisms of CDH6 and CDH11 in the progression of several types of cancer are not completely understood. CDH6 has been suggested to promote EMT during tumor development and progression by mediating pro-EMT signals (33). CDH6 affects the activity of F-actin and Rho GTPase, which is important for cell motility and EMT (34). EMT is a complex change in the cell phenotype that is important for cell migration and carcinoma metastasis. A previous study also demonstrated that CDH6 is a novel transforming growth factor (TGF)- $\beta$ target gene during EMT in thyroid tumors and that its expression is controlled by TGF- $\beta$ pathway molecules, including the Smad pathway or the phosphoinositide 3-kinase (PI3K)/protein kinase B (Akt) pathway (35).

During EMT, cadherin expression changes (cadherin switching), including $\mathrm{E}$ - to $\mathrm{N}$-cadherin switching, is associated with cancer metastatic occurrence (36). CDH6 to CDH11 switching is also involved in the EMT (37). The present study also indicated that $\mathrm{CDH} 6$ is associated with $\mathrm{CDH} 11$, and that overexpression of CDH11 is associated with LNM. Although high expression of CDH11 alone was not associated with a low overall survival rate in the OSCC cohort of the present study, it 

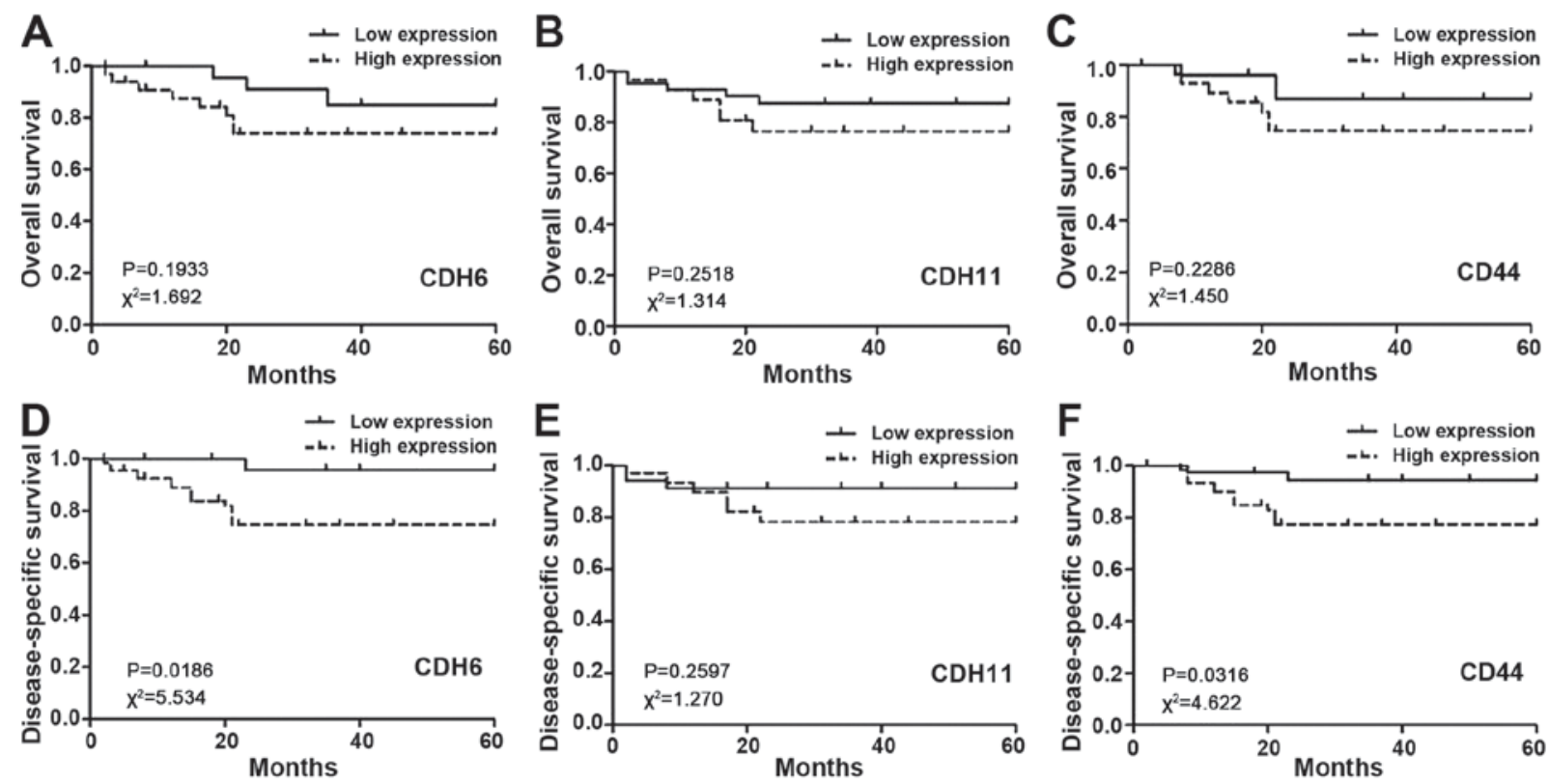

Figure 2. Association between CDH6, CDH11 or CD44 expression and survival in OSCC patients. Overall survival rate of OSCC patients with high or low expression of (A) CDH6, (B) CDH11 and (C) CD44. Disease-specific survival rate of OSCC patients with high or low expression of (D) CDH6, (E) CDH11 and (F) CD44 were analyzed using Prism software. P-values and $\chi^{2}$ values demonstrate statistically significant differences. CDH, cadherin; CD44, cluster of differentiation; OSCC, oral squamous cell carcinoma.
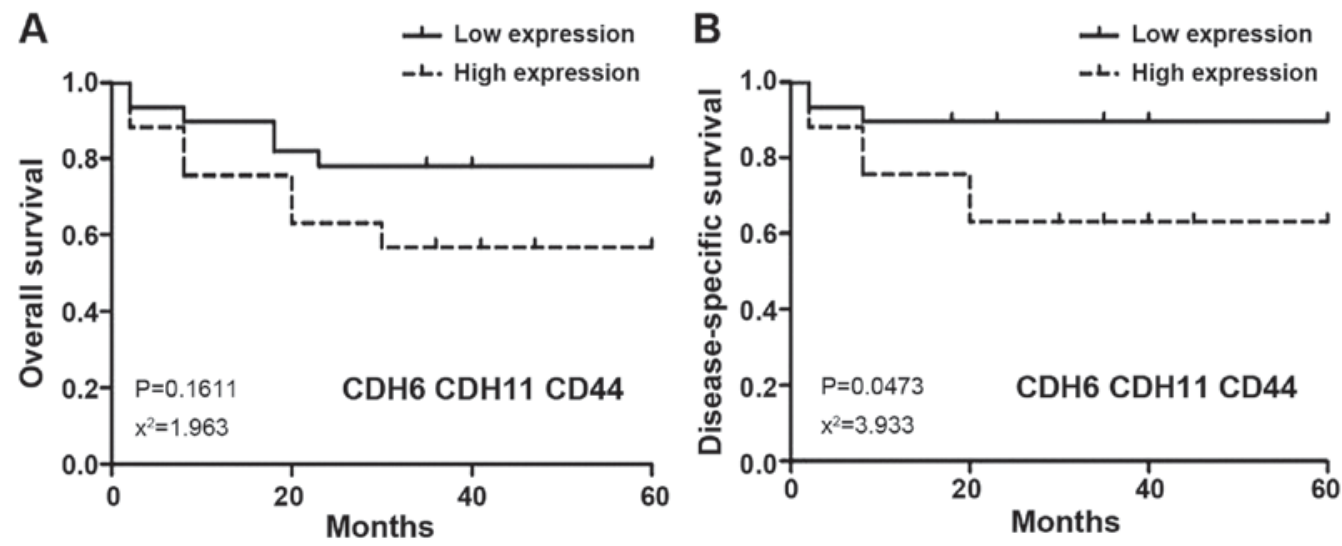

Figure 3. Association between co-expression of CDH6, CDH11 and CD44, and survival in patients with OSCC. (A) Overall and (B) disease-specific survival rates of patients with OSCC exhibiting high or low co-expression of CDH6, CDH11 and CD44 were analyzed using Prism software. P-values and $\chi^{2}$ values demonstrate statistically significant differences. $\mathrm{CDH}$, cadherin; $\mathrm{CD} 44$, cluster of differentiation 44; OSCC, oral squamous cell carcinoma.

was a statistically significant prognostic factor in several types of cancer, through its participation in EMT (38). However, the prognostic value was enhanced by co-evaluating the expression of CDH6, CDH11 and CD44 in the present study. Previous studies have reported that $\mathrm{CDH} 11$ interacts with angiomotin (Amot) to promote the migration of cancer cells. Amot is known to be involved in cell polarity and migration $(39,40)$. The Amot $\mathrm{p} 80$ isoform was revealed to regulate apical polarity by interacting with Rich1 (39), a small GTPase-activating protein, and to affect proliferation (41). CDH11 also regulates $\alpha$-catenin turnover at the adherens junctions, facilitating the dynamic remodeling of cell-cell interactions, which are important for inter-cellular invasion $(42,43)$. CDH11 was associated with signal transduction molecules, including the PI3K/Akt pathway (44).
In the present study, CD44 was revealed to be significantly associated with LNM, suggesting that CD44 is also involved in OSCC metastasis. These results are consistent with those of previous studies, which revealed that upregulation of CD44 represents a crucial event in the development of metastasis and that silencing CD44 expression suppressed its tumorigenic effects, including proliferation, migration and invasion in ovarian cancer and breast cancer cells $(45,46)$. CD44 interacts with c-Src kinase to regulate the mitogen-activated protein kinase (MAPK), PI3K and signal transducer and activator of transcription 3 pathways (47). The MAPK and PI3K/Akt/mechanistic target of rapamycin pathways have been demonstrated to promote cancer cell proliferation and to enhance invasiveness and angiogenesis (18). In addition, a previous study revealed that CD44 expression is associated 
with EMT and LNM in patients with OSCC (48). The present study revealed that CD44 was significantly associated with cadherins, including CDH6 and CDH11, and that its expression was also associated with the PI3K/Akt pathway. Therefore, it may be beneficial to combine these adhesion factors as metastasis-predictive parameters in order to improve their prognostic value, as multiple signal pathways, including the MAPK and PI3K/Akt pathways, may be involved in the metastasis of OSCC.

In conclusion, the present study demonstrated that the high expression of CDH6, CDH11 and CD44 in OSCC cells was significantly associated with an increased propensity to develop LNM and an advanced tumor stage. A positive association between CD44, CDH6 and CDH11 protein expression in OSCC patients was also observed in the present study. The combined use of these factors may improve the accuracy of metastasis and prognosis prediction. The results of the present study highlighted the important role of these adhesion factors in the progression of OSCC, which may provide a novel perspective in the prediction and prevention of metastasis in OSCC.

\section{Acknowledgements}

The authors would like to thank Miss Xiaoliang Jiang for providing editorial and technical assistance.

\section{Funding}

The present study was supported by grants from the National Natural Science Foundation of China (grant no. 81250043) and the Natural Science Foundation of Beijing Municipality (grant no. 7142135).

\section{Availability of data and materials}

The datasets used and/or analyzed during the current study are available from the corresponding author on reasonable request.

\section{Authors' contributions}

CM drafted the article, designed the study and analyzed the data. JZ, RL, LZ, YC and LY collected and analyzed the data. TS, MW, ML and YL performed the experiments and collected the data. TZ designed the study, secured the funding and performed critical revision of the article.

\section{Ethics statement and consent to participate}

The study was approved by the Ethics Committee of Peking Union Medical College.

\section{Consent for publication}

All patients provided written informed consent for the publication of associated data and accompanying images.

\section{Competing interests}

The authors declare that they have no competing interests.

\section{References}

1. Slootweg PJ and Eveson JW (eds): Tumours of the oral cavity and oropharynx. In: World Health Organization Classification of Tumours. Pathology \& Genetics of Head and Neck Tumours. IARC Press, Lyon, pp166-167, 2005.

2. Okura M, Aikawa T, Sawai N, Lida S and Kogo M: Decision analysis and ent threshold in a management for the N0 neck of the oral cavity carcinoma. Oral Oncol 45: 908-911, 2009.

3. Lea J, Bachar G, Sawka AM, Lakra DC, Gilbert RW, Irish JC, Brown DH, Gullane PJ and Goldstein DP: Metastases to level IIb in squamous cell carcinoma of the oral cavity: A systematic review and meta-analysis. Head Neck 32: 184-190, 2010.

4. Fan S, Tang QL, Lin YJ, Chen WL, Li JS, Huang ZQ, Yang ZH Wang YY, Zhang DM, Wang HJ, et al: A review of clinical and histological parameters associated with contralateral neck metastases in oral squamous cell carcinoma. Int J Oral Sci 3: 180-191, 2011.

5. Noguti J, De Moura CF, De Jesus GP, Da Silva VH, Hossaka TA Oshima CT and Ribeiro DA: Metastasis from oral cancer: An overview. Cancer Genomics Proteomics 9: 329-336, 2012.

6. Thiery JP, Acloque H, Huang RY and Nieto MA: Epithelial-mesenchymal transitions in development and disease. Cell 139: 871-890, 2009.

7. Nelson WJ and Nusse R: Convergence of Wnt, beta-catenin, and cadherin pathways. Science 303: 1483-1487, 2004.

8. Huber GF, Züllig L, Soltermann A, Roessle M, Graf N, Haerle SK, Studer G, Jochum W, Moch H and Stoeckli SJ: Down regulation of E-Cadherin (ECAD)-a predictor for occult metastatic disease in sentinel node biopsy of early squamous cell carcinomas of the oral cavity and oropharynx. BMC Cancer 11: 217:1-8, 2011.

9. Zhao Z, Ge J, Sun Y, Tian L, Lu J, Liu M and Zhao Y: Is E-cadherin immunoexpression a prognostic factor for head and neck squamous cell carcinoma (HNSCC)? A systematic review and meta-analysis. Oral Oncol 48: 761-767, 2012.

10. Thedieck C, Kuczyk M, Klingel K, Steiert I, Müller CA and Klein G: Expression of Ksp-cadherin during kidney development and in renal cell carcinoma. Br J Cancer 92: 2010-2017, 2005.

11. Fluge $\varnothing$, Bruland O, Akslen LA, Lillehaug JR and Varhaug JE: Gene expression in poorly differentiated papillary thyroid carcinomas. Thyroid 16: 161-175, 2006.

12. Sancisi V, Gandolfi G, Ragazzi M, Nicoli D, Tamagnini I, Piana S and Ciarrocchi A: Cadherin 6 is a new RUNX2 target in TGF- $\beta$ signalling pathway. PLoS One 12: e75489, 2013.

13. Chu K, Cheng C J, Ye X, Lee YC, Zurita AJ, Chen DT, Yu-Lee LY, Zhang S, Yeh ET, Hu MC, et al: Cadherin-11 promotes the metastasis of prostate cancer cells to bone. Mol Cancer Res 6: 1259-1267, 2008.

14. Huang CF, Lira C, Chu K, Bilen MA, Lee YC, Ye X, Kim SM, Ortiz A, Wu FL, Logothetis CJ, et al: Cadherin-11 increases migration and invasion of prostate cancer cells and enhances their interaction with osteoblasts. Cancer Res 70: 4580-4589, 2010.

15. Chou YE, Hsieh MJ, Hsin CH, Chiang WL, Lai YC, Lee YH, Huang SC, Yang SF and Lin CW: CD44 gene polymorphisms and environmental factors on oral cancer susceptibility in Taiwan. PLoS One 9:e93692, 2014.

16. Shakib PA, Ensani F, Abdirad A, Valizadeh B, Seyedmajidi M and Sum S: CD44 and CD74: The promising candidates for molecular targeted therapy in oral squamous cell carcinoma. Dent Res J (Isfahan) 12: 181-186, 2015.

17. Joshua B, Kaplan MJ, Doweck I, Pai R, Weissman IL, Prince ME and Ailles LE: Frequency of cells expressing CD44, a head and neck cancer stem cell marker: Correlation with tumor aggressiveness. Head Neck 34: 42-49, 2012.

18. Judd NP, Winkler AE, Murillo-Sauca O, Brotman JJ, Law JH, Lewis JS Jr, Dunn GP, Bui JD, Sunwoo JB and Uppaluri R: ERK1/2 regulation of CD44 modulates oral cancer aggressiveness. Cancer Res 72: 365-374, 2012.

19. Edge SB, Byrd DR, Compton CC, Fritz AG, Greene F and Trotti A (eds): AJCC cancer staging manual. 7th edition. Springer-Verlag, New York, pp347-377, 2010.

20. Livak KJ and Schmittgen TD: Analysis of relative gene expression data using real-time quantitative PCR and the 2(-Delta Delta C(T)) method. Methods 25: 402-408, 2001.

21. Yoshihama R, Yamaguchi K, ImajyoI, Mine M, Hiyake N, Akimoto N, Kobayashi Y, Chigita S, Kumamaru W, Kiyoshima T, et al: Expression levels of SOX2, KLF4 and brachyury transcription factors are associated with metastasis and poor prognosis in oral squamous cell carcinoma. Oncol Lett 11: 1435-1446, 2016. 
22. Yang H, Liang J, Zhou J, Mi J, Ma K, Fan Y, Ning J, Wang C, Wei $X$ and Li E: Knockdown of RHOC by shRNA suppresses invasion and migration of cholangiocellular carcinoma cells via inhibition of MMP2, MMP3, MMP9 and epithelial-mesenchymal transition. Mol Med Rep 13: 5255-5261, 2016.

23. Bradbury R, Jiang WG and Cui YX: MDM2 and PSMA Play inhibitory roles in metastatic breast cancer cells through regulation of matrix metalloproteinases. Anticancer Res 36: 1143-1151, 2016.

24. Mendonsa AM, VanSaun MN, Ustione A, Piston DW Fingleton BM and Gorden DL: Host and tumor derived MMP13 regulate extravasation and establishment of colorectal metastases in the liver. Mol Cancer 14: 49, 2015.

25. Bonecchi R, Galliera E, Borroni EM, Corsi MM, Locati M and Mantovani A: Chemokines and chemokine receptors: An overview. Front Biosci 14: 540-551, 2009.

26. Chinn SB and Myers JN: Oral cavity carcinoma: current management, controversies, and future directions. J Clin Oncol 33: 3269-3276, 2015

27. Ashaie MA and Chowdhury EH: Cadherins: The superfamily critically involved in breast cancer. Curr Pharm Des 22: 616-638, 2016.

28. Zhou J, Tao D, Xu Q, Gao Z and Tang D: Expression of E-cadherin and vimentin in oral squamous cell carcinoma. Int J Clin Exp Pathol 8: 3150-3154, 2015

29. Alaee M, Danesh G and Pasdar M: Plakoglobin reduces the in vitro growth, migration and invasion of ovarian cancer cells expressing N-cadherin and mutant p53. PLoS One 11: e0154323, 2016.

30. Paul R, Necknig U, Busch R, Ewing CM, Hartung R and Isaacs WB: Cadherin-6: A new prognostic marker for renal cell carcinoma. J Uro 171: 97-101, 2004.

31. Satcher RL, Pan T, Bilen MA, Li X, Lee YC, Ortiz A, Kowalczyk AP, Yu-Lee LY and Lin SH: Cadherin-11 endocytosis through binding to clathrin promotes cadherin-11-mediated migration in prostate cancer cells. J Cell Sci 128: 4629-4641, 2015.

32. Ortiz A, Lee YC, Yu G, Liu HC, Lin SC, Bilen MA, Cho H, $\mathrm{Yu}-\mathrm{Lee} \mathrm{LY}$ and Lin SH: Angiomotin is a novel component of cadherin-11/ $\beta$-catenin/p120 complex and is critical for cadherin-11-mediated cell migration. FASEB J 3: 1080-1091, 2015.

33. Clay MR and Halloran MC: Cadherin 6 promotes neural crest cell detachment via F-actin regulation and influences active Rho distribution during epithelial-to-mesenchymal transition. Development 141: 2506-2515, 2014.

34. Bravo-Cordero JJ, Moshfegh Y, Condeelis J and Hodgson L: Live cell imaging of RhoGTPase biosensors in tumor cell. Methods Mol Biol 1046: 359-370, 2013.

35. Sancisi V, Gandolfi G, Ragazzi M, Nicoli D, Tamagnini I, Piana S and Ciarrocchi A: Cadherin 6 is a new RUNX2 target in TGF- $\beta$ signalling pathway. PLoS One 8: e75489, 2013.
36. Wheelock MJ, Shintani Y, Maeda M, Fukumoto Y and Johnson KR: Cadherin switching. J Cell Sci 121: 727-735, 2008.

37. Bringuier PP, Schalken JA, Hervieu V and Giroldi LA: Involvement of orphan nuclear receptor COUP-TFII in cadherin- 6 and cadherin-11 regulation: Implications in development and cancer. Mech Dev 136: 64-72, 2015.

38. Satcher RL, Pan T, Cheng CJ, Lee YC, Lin SC, Yu G, Li X, Hoang AG, Tamboli P, Jonasch E, et al: Cadherin-11 in renal cell carcinoma bone metastasis. PLoS One 9: e89880, 2014.

39. Wells CD, Fawcett JP, Traweger A, Yamanaka Y, Goudreault M, Elder K, Kulkarni S, Gish G, Virag C, Lim C, et al: A Rich1/Amot complex regulates the $\mathrm{Cdc} 42$ GTPase and apical-polarity proteins in epithelial cells. Cell 125: 535-548, 2006.

40. Ernkvist M, Luna Persson N, Audebert S, Lecine P, Sinha I, Liu M, Schlueter M, Horowitz A, Aase K, Weide T, et al: The Amot/Patj/Syx signaling complex spatially controls RhoA GTPase activity in migrating endothelial cells. Blood 113: 244-253, 2009.

41. Yi C, Troutman S, Fera D, Stemmer-Rachamimov A, Avila JL, Christian N, Persson NL, Shimono A, Speicher DW, Marmorstein R, et al: A tight junction-associated Merlin-angiomotin complex mediates Merlin's regulation of mitogenic signaling and tumor suppressive functions. Cancer Cell 19: 527-540, 2011.

42. Feltes CM, Kudo A, Blaschuk O and Byers SW: An alternatively spliced cadherin-11 enhances human breast cancer cell invasion. Cancer Res 62: 6688-6697, 2002.

43. Kiener HP, Stipp CS, Allen PG, Higgins JM and Brenner MB The cadherin-11 cytoplasmic juxtamembrane domain promotes alpha-catenin turnover at adherens junctions and intercellular motility. Mol Biol Cell 17: 2366-2375, 2006.

44. Wu M, Xu T, Zhou Y, Lu H and Gu Z: Pressure and inflammatory stimulation induced increase of cadherin-11 is mediated by PI3K/Akt pathway in synovial fibroblasts from temporomandibular joint. Osteoarthritis Cartilage 21: 1605-1612, 2013.

45. Gao Y, Foster R, Yang X, Feng Y, Shen JK, Mankin HJ, Hornicek FJ, Amiji MM and Duan Z: Up-regulation of CD44 in the development of metastasis, recurrence and drug resistance of ovarian cancer. Oncotarget 6: 9313-9326, 2015.

46. Xu H, Tian Y, Yuan X, Liu Y, Wu H, Liu Q, Wu GS and Wu K: Enrichment of CD44 in basal-type breast cancer correlates with EMT, cancer stem cell gene profile, and prognosis. Onco Targets Ther 9: 431-444, 2016.

47. Hynes NE and Lane HA: ERBB receptors and cancer: The complexity of targeted inhibitors. Nat Rev Cancer 5: 341-354, 2005.

48. Ghuwalewala S, Ghatak D, Das P, Dey S, Sarkar S, Alam N, Panda CK and Roychoudhury S: CD44(high)CD24(low) molecular signature determines the Cancer Stem Cell and EMT phenotype in oral squamous cell carcinoma. Stem Cell Res 16: 405-417, 2016. 